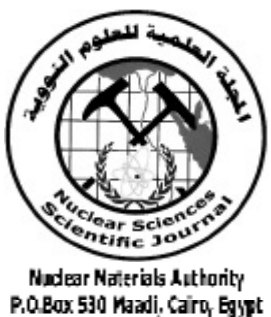

ISSN 2314-5609

Nuclear Sciences Scientific Journal

5, 197-208

2016

http://www.ssnma.com

\title{
GRAB SAMPLING AND CONTINUOUS MONITORING TECHNIQUES FOR RADON MEASUREMENTS AT CONTROLLED ENVIRONMENTAL CONDITIONS
}

\author{
SAYED F. HASSAN; MOUSTAFA N. TAWFIK; MAHMOUD H. SHALABY; \\ MOHAMED I. HUSSIEN ${ }^{1}$ and IBRAHIM H. IBRAHIM ${ }^{2}$ \\ Nuclear materials authority, Cairo, Egypt; ${ }^{1}$ National centre for nuclear safety, atomic energy authority; \\ ${ }^{2}$ physics Dept., Fac. Sci., Ain shams univ.
}

\begin{abstract}
The continuous monitoring of radon gas concentration is a useful method for studying the effects of ventilation on radon concentration levels. The determination of average radon concentration is more preferable than the active-type. For this purpose, a model chamber of cubic shape made of plexy-glass

Radon calibration chamber is a good tool for testing radon measurements for different devices and techniques, a $0.65 \mathrm{~m}^{3}$ plexy-glass chamber was constructed to compare between different detecting devices with the change of environmental conditions (temperature-relative humidity-samples concentration) as well as the use of devices inside or outside the chamber. This chamber resembles to a great extend the mines atmosphere which helps in using it as a pilot plant.

For this purpose, two devices (RDA-200 and TRI-MET 372) are used for active-type. (RGM 1/1 and CRM-1027) devices are used for continuous monitoring. The experiments are carried out at two different environmental conditions, one by using high temperature $\left(40^{\circ} \mathrm{C}\right)$ and relative humidity $(100 \%)$, the other by using low temperature $\left(16^{\circ} \mathrm{C}\right)$ and low relative humidity $(50 \%)$.

The obtained results show that, lower stability in the measurements with the change in environmental conditions. More stability for the RDA - 200 and Tri-Met devices at high temperature and high humidity was observed. From the other hand, a more stability for both RGM and CRM devices is clearly appeared at low temperature and low humidity conditions. This may be attributed to that the measurements depend mainly on an electronic circuit which has a higher performance at these environmental conditions.
\end{abstract}

\section{INTRODUCTION}

There are two main categorized measuring techniques, active technique and passive technique.

The Grab Sampling Techniques (Activetype): In this case, air is sampled by drawing it through a filter material, housed in an adequate filter holder by means of air sampling pump. Radioactivity counting is carried out after the sampling period.
i)Rn-gas measurements. The examined air sample is collected by filling a container, either previously evacuated or by a flowthrough type in the sampling area and releasing the container. The radon from the sample is then later (may be days later) transferred to a measuring chamber such as ionization chamber or scintillation cell (Lucas,1957).

An integrated count method has been described previously (Jonassen and 
Clements, 1974)., where the counting of radon activity may start at any time after filling the cell with daughter-free air. The accuracy of the method is shown to depend on the counting period rather than upon the time elapsed since filling. Another active method for measuring radon concentration using a metal cylinder and two filters (two filter method). In this case air is drawn through a cylinder fitted with a filter on either end. The front filter will remove all daughters in the air sampled, and the second filter will collect those daughters' products being produced by decaying of radon in the air, while it passes through the cylinder. The alpha activity from the filter at the end of sampling is then a measure of the radon concentration in the sampled air, Fontan et al.(1962), Jacobi (1964), Thomas and Le Clare (1970).

The measurement of radon daughters: It is often used not only for the determination of individual daughter concentrations but also for measurement (or estimation) of the potential alpha energy concentration of these daughters (WL). All methods used for both types of measurements are based on the analysis of the activity from a filter (or detector) on which the daughters have been deposited. The daughter's activity from the filter may be counted during and/or after sampling( Evans, 1969). If the air is drown through a filter, and the gross alpha activity is counted after waiting certain period for one time this called one count method Kusntez (1956) and Rolle (1972) methods, which differ only in the choice of sampling, waiting and counting times. To overcome the low accuracy in the one count methods a lengthy operating procedure uses two uncorrelated counts.

The most common two-count method is the Hill Method Hill (1975). The total alpha activity is integrated over two counting periods of two minutes after the end of sampling with the integrated counts $I_{0}$ and $I_{1}$, respectively. Using a special relation including this ratio and detector efficiency, the (PAEC) can be calculated. Methods for three uncorrected counts during and /or after sampling is called three-count methods, there are two techniques for the three count methods:

i) Alpha gross count method, where the sum of RaA and RaĆ activities is measured. The most commonly used $\alpha$-gross count method was developed by Tsivoglou et al. (1953) in which the activity from a filter is measured at three intervals after sampling. The amount of air sampled is about 50 liters. Because count rates are used instead of integrated counts, even at high concentrations (tens of thousands $\mathrm{Bq} / \mathrm{m}^{3}$ ), the reproducibility may only be good within 20-30 percent. By integrating the alpha activity over time intervals instead of measuring the rate at three times, it is possible to reduce the uncertainty of the Tsivoglou method considerably as proposed by Thomas (1972).

The uncertainty is usually high for RaA, especially if the atmosphere is near radioactive equilibrium. From three different grossalpha count rates it is possible to calculate the concentrations of RaA (Po-218), RaB (Pb214) and $\mathrm{RaC}(\mathrm{Bi}-214)$, by solving a system of three Bateman linear differential equations with three unknowns (Evans, 1969).

ii) Alpha spectroscopy methods, where $\mathrm{RaA}$ and $\mathrm{RaC}$ activities are measured individually. In these methods, the alpha particles from radon daughters can be counted separately and the daughter concentration can be obtained by distinguishing between the 6-MeV and 7.69 MeV alpha particles energy groups. A method employing only alpha radiation has been developed by Martz et al. (1969).

In case of Continuous Monitoring Techniques: air samples are taken on a continuous basis lasting typically from several days to several weeks. Counting of radioactivity is conducted by the same instrument and concurrently with air sampling. Hence, the radioactivity count, or activity is being "inte- 
grated" by the instrument. Also, the continuous monitoring of radon concentrations is the most useful method for studying the effects of ventilation on radon concentration levels and determination of average radon concentration.

In continuous monitoring of radon daughters, the air is sampled continuously and the alpha and/or beta activities are integrated over intervals ranging from minutes to hours (Dalu and Dalu ,1971), Thomas (1977) and Wrenn et al. (1975).

In radon daughter measurement systems, the daughters are collected on a filter, which is placed in front of a detector. A common calibration procedure uses an essentially mono-energetic alpha emitter, americium241, uniformly deposited on a metal disc as pseudo radon daughter calibration source. An absolute method for calibration of radon daughter system has been developed by Falk (1982). Beckman (1975) described calibration of air sampling equipment and counting equipment including field checks, calibration equipment and data treatment. For radon daughter calibration, Thomas (Modified Tsivoglou) and alpha spectrometric methods have been suggested as the most suitable primary counting methods Lawrence Berkeley Laboratory (1981).

\section{EXPERIMENTAL TECHNIQUES}

\section{Calibration Chamber and Samples}

The chamber is made of $(0.5 \mathrm{~cm}$ thick) plexy glass sheets. It is of cubic shape with volume of $0.65 \mathrm{~m}^{3}$. On top, a removable ceiling contains four wholes of $(1 \mathrm{~cm}$ in diameter) each. Two holes are used for the intake of samples from the chamber, the other two are used for the electricity cables needed for the devices inside the chamber. It has also the possibility for using active techniques for radon and its daughter's detection (Tawfik, 2011) Fig.1.

Five different samples were selected from Gattar Mountain (Hurghada, Red Sea, Egypt).
The uranium content of these samples was experimentally measured in the NMA Laboratories, Salem, 2008. The chosen samples are nearly equal weight, size, and physical state (solid rocks) with no fractures or any crushing to smaller grains. The samples are labelled from one to five according to their uranium ppm measurements as follows: Sample 1 (35 ppm), sample 2 (200 ppm), sample 3 (330 ppm), sample 4 (470 ppm), sample 5 (850 ppm).

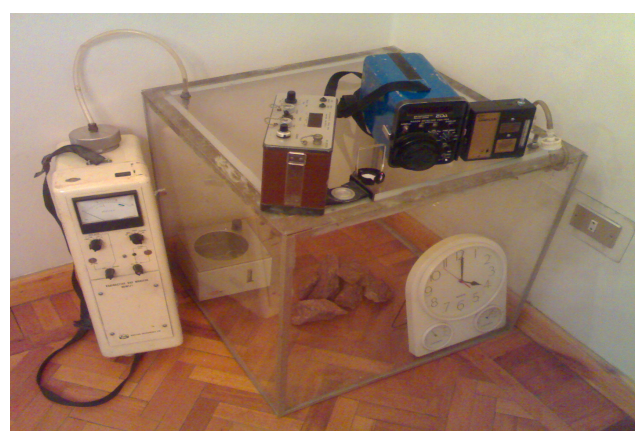

Fig. 1: Radon calibration chamber

\section{Devices and Methods}

A total of four devices are used, two of them (RDA-200 and TRI-MET 372 for the grab sampling (active) techniques.

i) RDA-200: It is designed to measure alpha activity originated from radon and its daughters. The alpha particles register on the $\mathrm{ZnS}$ (Ag) phosphor coating of the scintillator cell or tray in the form of light flashes. Each flash of light, as seen by the high gain photomultiplier tube, is transformed into an electrical impulse. These impulses are accumulated, counted and then digitally displayed on a five digit, seven segments L.E.D. digital display, after a preset counting time has been completed. The device weight is about $3 \mathrm{~kg}$. (EDA Instruments INC).

ii) TRI-MET 372: It is designed as an alpha counter, equipped with a foil type open Zinc Sulphide detector. The instrument is 
manufactured by (Tri-Met Instruments LTD). This type of detector is inexpensive, readily obtainable and is easily replaced. The sample holders can accommodate membrane filter samples of $25 \mathrm{~mm}, 37 \mathrm{~mm}$. and $47 \mathrm{~mm}$ diameter. The device weight is about $2.5 \mathrm{~kg}$, the Tri-Met was used for measuring (WL) by Roll-method, (Tri-Met instruments LTD).

The second category (continuous radon gas monitoring)

iii)Portable Radioactive Gas Monitor type RGM 1/1 is a self-contained instrument for measuring the concentration of radioactive gases in air, it is calibrated for Tritiated Water Vapour (HTO) in air, for direct radon gas determination; a single portable, battery operated device is used to monitor radon gas. The device is of weight $(14.5 \mathrm{Kg})$, (Nuclear Enterprises Ltd).

iv) Professional continuous radon monitor model (CRM-1027) is a patented electronic detecting device using a diffused-Junction photodiode sensor to measure the concentration of radon gas. The unit is operated from standard line power and includes a 9-volt battery which provides backup power. For continuous radon monitoring; a single fixed, electricity operated device is used for monitoring of radon gas. It has an internal detector for measuring radon gas and it is equipped with a digital screen for displaying of results. It has a weight of (1 Kg), (Sun Nuclear Corporation).

\section{Measuring Procedures}

The experiment is done according to the variable factors, the plan can be divided into two parts: one using high temperature $\left(40^{\circ} \mathrm{C}\right)$ and relative humidity $(100 \%)$ conditions and the other by using low temperature $\left(16^{\circ} \mathrm{C}\right)$ and low relative humidity $(50 \%)$.

Each sample is put separately inside the radon chamber and the measurements started from zero time till 168 hours (one week), the measurements are taken for all devices at the same time every four hours resulting in 42 measurements for each device. The tempera- ture is adjusted to reach $40^{\circ} \mathrm{C}$ and a by using a water bath as water source to ensure a relative humidity level of $100 \%$ (Tawfik, 2011).

The experimental techniques could be described as follows:

1)For the total potential alpha energy concentration expressed as working level PAEC: Rolle method is used, using a portable air sampler to withdraw up to $5 \mathrm{l} / \mathrm{min}$ of air through a filter paper.

Radon daughters are collected on a highefficiency filter paper for 10 minutes and then alpha-counted with either a rate meter or scalar after a prescribed delay of about 5 to 10 minutes (Rolle, 1968).

The Working Level is calculated by the following formula Safety Series No. 43, (1979):

$$
W L=\frac{R-B}{E v t F}
$$

Where:

$\mathrm{R}=$ Count rate at $\mathrm{T}$ minutes from the end of sampling (in counts/min)

$\mathrm{B}=$ Count rate due to background measurement

$\mathrm{E}=$ Counting efficiency, decimal fraction

$\mathrm{v}=$ Volumetric sampling rate in $\mathrm{L} / \mathrm{min}$

$\mathrm{t}=$ Sampling time in minutes

$\mathrm{F}=$ Conversion factor $=212$ for sampling periods of from 1 to $20 \mathrm{~min}$

2) For direct radon gas measurement using RGM 1/1: The technique starts by withdrawing a sample of air by the air pump followed by a direct measurement by ionization chamber detector to obtain the result in a few seconds from sampling (Grossi, 2001).

3)For continuous radon monitoring: A sensitive semiconductor detector is exposed to radon to start the measuring processes, by this way the radon can be continuously monitored. These values are stored using a small internal memory for future revision.

The annual dose conversion factors were done as follows:

1) The total working hours per one year will be two thousand (2000) hours per year. 
The ICRP-31,1980 (International Commission for Radiation Protection) submits a conversion factor $(\mathrm{CF})$ ) for the calculation of annual dose from the WLM to be five times greater, so according to the previous information the final formula can be written as:

Annual dose $(\mathbf{m S v} / \mathbf{y})=\frac{(W L) X(2000 h) X(5 C F)}{(170 h)}$

2)The calculation of annual dose using the data information from the RGM 1/1 (Radioactive Gas Monitor) which gives the data in $\mu \mathrm{Ci} / \mathrm{m}^{3}$.

Annual dose $(\mathbf{m S v} / \mathbf{y})=\frac{\left(\mu C i / m^{3}\right) X(1000 U C) X(0.2331 C F)}{(1000 D U C)}$

3)The calculation of annual dose using the data information from the CRM -1027 (Continuous Radon Monitoring) which gives the data in $\mathrm{pCi} / 1$.

Annual dose $(\mathbf{m S v} / \mathbf{y})=(p C i / l) X(0.2331 C F)$

Where :

$\mathbf{U C}$ : is the unit conversion from $\mu \mathrm{Ci} / \mathrm{m}^{3}$ to $\mathrm{pCi} / 1$.

DUC: is the device conversion factor from Tritiated Water Vapour (HTO) in air to $\mu \mathrm{Ci} / \mathrm{m}^{3}$.

\section{RESULTS AND DISCUSSION}

\section{Active Techniques (Grab Sampling) one Count Method}

\section{At High temperature and humidity}

For the Tri-Met 372, Figure (2) shows the experimental results of the calculated annual doses using equation (2) with the five samples where low annual doses $(\mathrm{mSv} / \mathrm{y})$ are reported for low sample concentrations and minimum time period $(4-20 \mathrm{~h})$ while high values for annual doses $(\mathrm{mSv} / \mathrm{y})$ are reported for maximum sample concentrations and maximum time periods (140-164 h)

At low samples concentrations a smooth increase in the calculated values are observed which indicate that the instrument was able to discriminate between small concentrations at the harsh environmental conditions. At high samples concentrations a high ability for the discrimination between high and low concentrations epically at the harsh environmental conditions was observed

For $R D A$ 200, Figure (3) shows the experimental results of the calculated annual doses using equation (2).

Low annual doses $(\mathrm{mSv} / \mathrm{y})$ were reported for low sample concentrations and minimum time period $(4-20 \mathrm{~h})$ while high values for annual doses $(\mathrm{mSv} / \mathrm{y})$ was reported for maximum sample concentrations maximum time periods $(140-163 \mathrm{~h})$

At low samples concentrations a smooth variation is observed which indicate that the instrument is able to discriminate between small concentrations at the harsh environmental conditions. Also it is shown that at high samples concentrations a complete separation between the measured values, which means

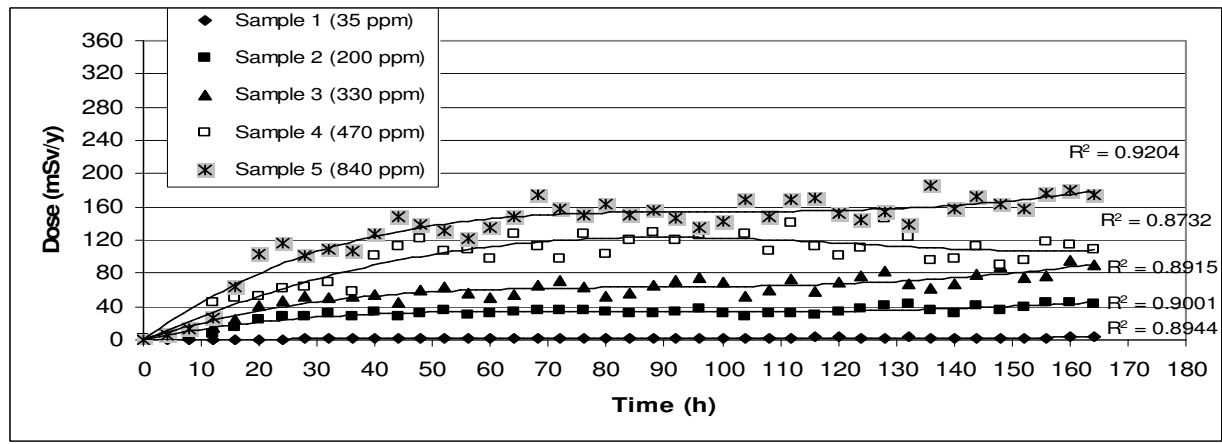

Fig. 2 : Calculated annual dose $(\mathrm{mSv} / \mathrm{y})$ using the measurements of Tri-Met device for all samples at high relative humidity and temperature versus time $(\mathrm{h})$ 


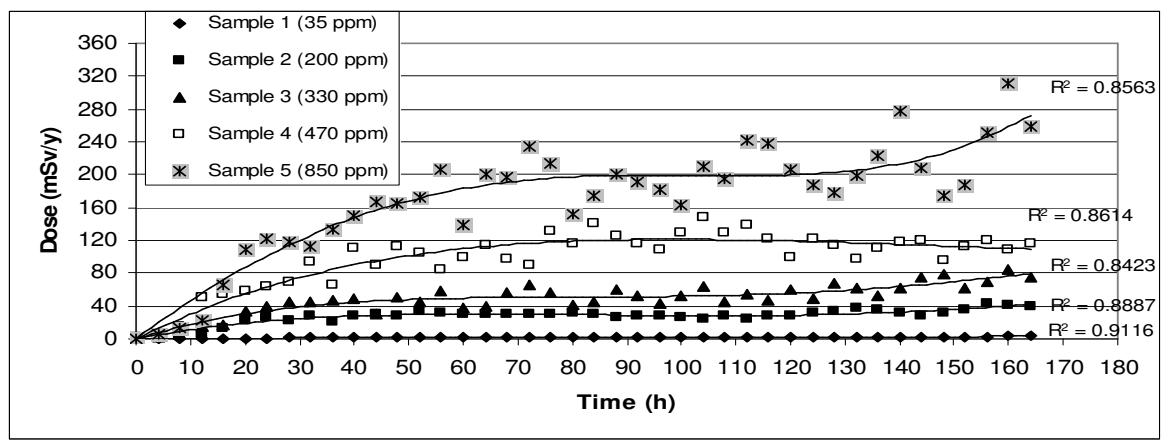

Fig. 3: Calculated annual dose (mSv/y) using the measurements of RDA 200 device for all samples at high relative humidity and temperature versus time (h)

that the instrument has the ability to discriminate between high and low concentrations at harsh environmental conditions that may give it advantages for using in such cases.

\section{At Low temperature and humidity}

For the Tri-Met 372, Figure (4) shows that low annual doses $(\mathrm{mSv} / \mathrm{y})$ are reported for low sample concentrations and minimum time period $(4-20 \mathrm{~h})$, while high values for annual doses $(\mathrm{mSv} / \mathrm{y})$ are reported for maximum sample concentrations maximum period $(140-164 \mathrm{~h})$.

From the table we can observe that there is an increase in the calculated annual doses with time when using different samples from sample (1) to sample (5). Nearly closed data appears for sample (2) and sample (3) and a slight overlap appears for sample (4) and sample (5).

There is some coincidence in some measured values in case of high and low samples concentrations where there is a complete difference between the two groups, which means that the instrument does not have the ability to discriminate between high and low samples concentrations at normal environmental conditions.

For $R D A$ 200, Figure (5) shows that low annual doses $(\mathrm{mSv} / \mathrm{y})$ are reported for low sample concentrations and minimum time pe$\operatorname{riod}(4-20 \mathrm{~h})$. While high values for annual doses $(\mathrm{mSv} / \mathrm{y})$ was reported for maximum sample concentrations maximum period (140 $-164 \mathrm{~h})$

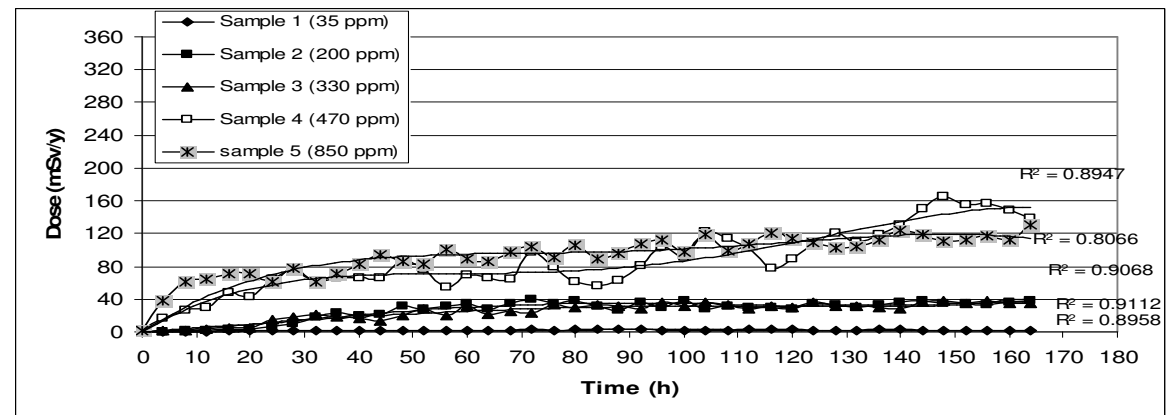

Fig. 4: Calculated annual dose (mSv/y) using the measurements of Tri - Met device for all samples at low relative humidity and temperature versus time (h) 


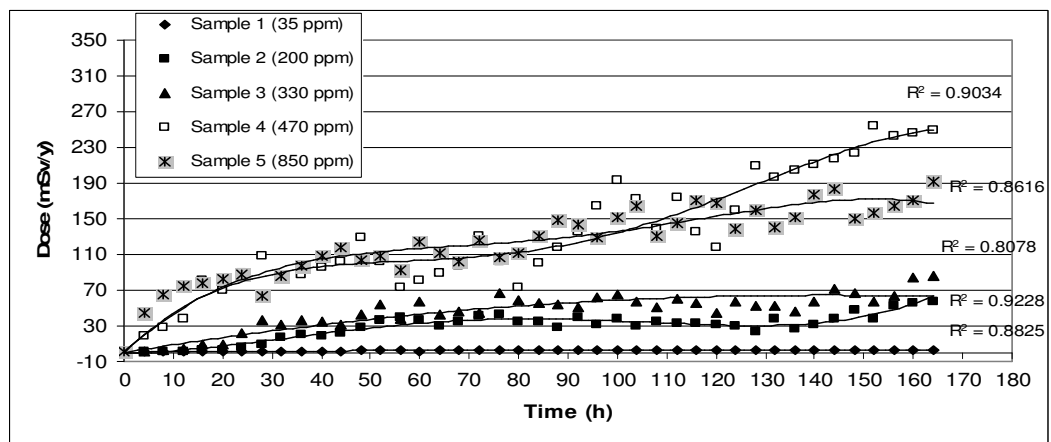

Fig. 5 : Calculated annual dose (mSv/y) using the measurements of RDA 200 device for all samples at low relative humidity and temperature versus time (h)

An increase in the calculated annual doses with time when using different samples, from sample (1) to sample (5). A slight overlap appears for sample (4) and sample (5).

At low samples concentrations a normal increase in the calculated annual dose with time is observed.

There is an overlap in some measured values in case of high and low samples concentrations where there is a complete separation between the two groups, which means that the instrument does not have the ability to discriminate between high and low samples concentrations at normal environmental conditions.

\section{Continuous Radon Monitoring}

\section{At High temperature and humidity}

For the RGM 1/1, Figure (6) shows the experimental results of the calculated annual doses using equation (3) for the five samples

It is obvious that there is a gradually increase in the annual doses measured in $(\mathrm{mSv} /$ y) goes from low sample concentrations and minimum time period $(4-20 \mathrm{~h})$ to maximum sample concentrations maximum period (140 $-164 \mathrm{~h})$.

At low samples concentrations a some what highly closed values are observed while in the measured annual dose values for the

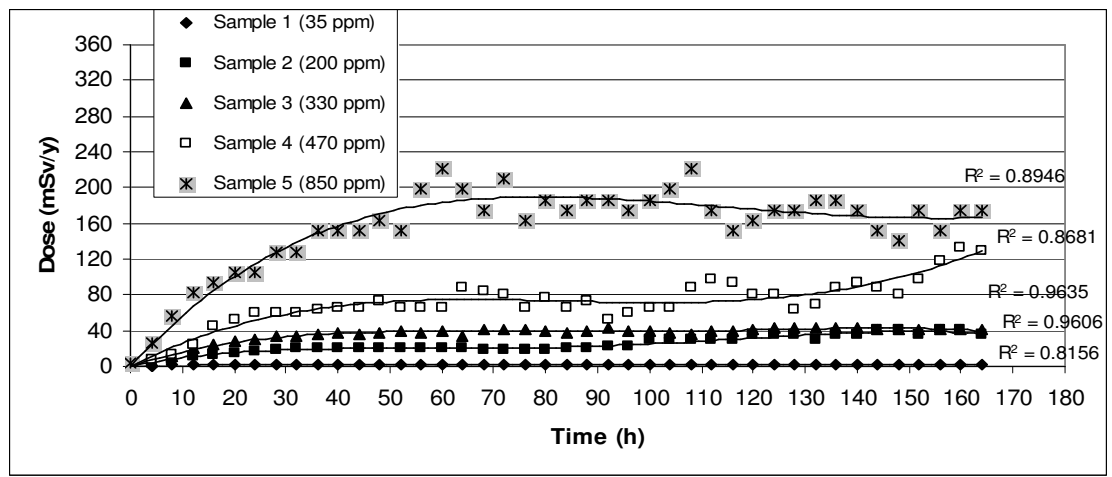

Fig. 6: Calculated annual dose (mSv/y) using the measurements of RGM 1/1device for all samples at high relative humidity and temperature versus time (h) 
most high two samples concentrations, there is a completely difference between them especially at high one $(850 \mathrm{ppm})$ indicating a low performance for this instrument, as it could not discriminate between high and low sample concentrations at harsh environmental conditions that may gives it disadvantages for being used in such cases.

For the CRM-1027, Figure (7) shows the experimental results of the calculated annual doses using equation (4) for the five samples

It is obvious that there is a gradual increase in the annual doses measured in ( $\mathrm{mSv} / \mathrm{y})$ that goes from low sample concentrations and minimum time period $(4-20 \mathrm{~h})$ to maximum sample concentrations maximum period (140 $-164 \mathrm{~h})$.

From the data we can get that: At low samples concentrations a highly closed values with small resolution and discrimination were observed. While for the high samples concentrations there is a close separation with small over lapping at small time intervals, which indicate a slightly confusion in the performance of the instrument at high and low concentrations at harsh environmental conditions.

\section{At Low temperature and humidity}

For the RGM 1/1, Figure (8) shows the experimental results of the calculated annual doses using equation (3) for the five samples. A gradual increase in the annual doses measured in $(\mathrm{mSv} / \mathrm{y})$ goes from low sample concentrations and minimum time period $(4-20$ h) to maximum sample concentrations maximum period $(140-164 \mathrm{~h})$

At low samples concentrations, highly smoothed minimum values are observed.

A complete separation between the measured values for the annual dose of low and

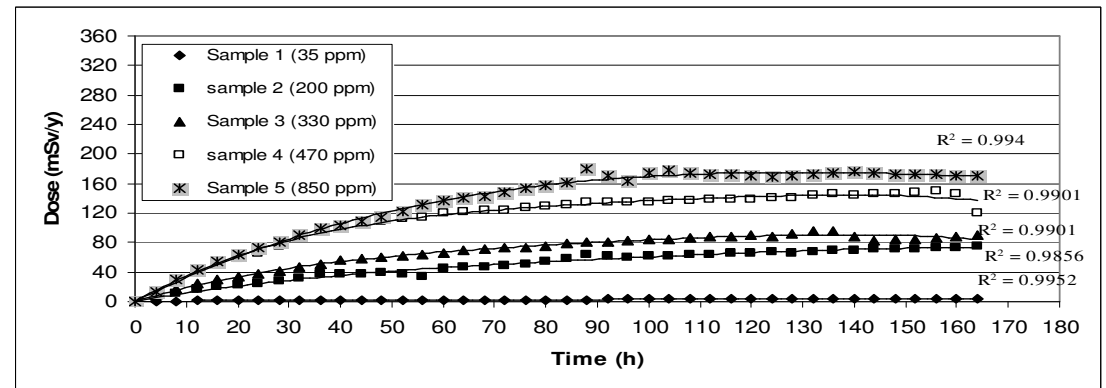

Fig. 7 : Calculated annual dose (mSv/y) using the measurements of CRM-1027device for all samples at high relative humidity and temperature versus time (h)

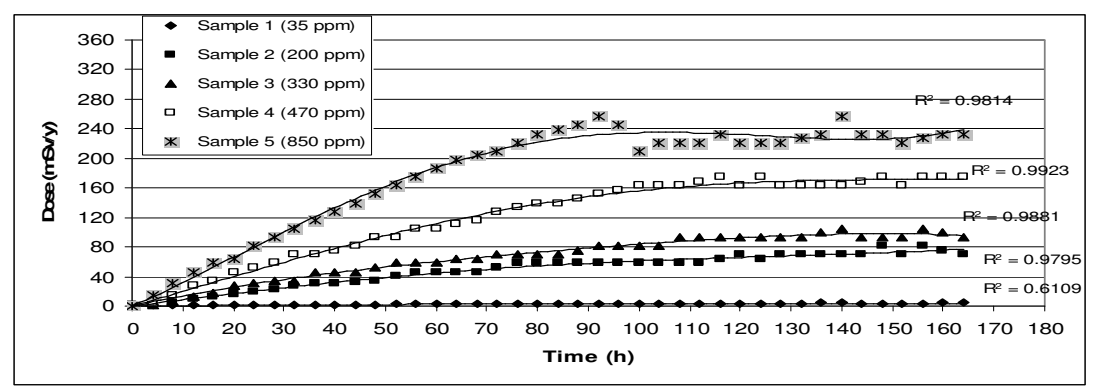

Fig. 8: Calculated annual dose (mSv/y) using the measurements of RGM 1/1device for all samples at low relative humidity and temperature versus time (h) 
high samples concentrations and at low and high values of temperature and humidity, which indicates a high performance for this instrument at high and low samples concentrations and at normal environmental conditions that may give it advantages to be used in such cases.

For the CRM- 1027, Figure (9): At low and high samples concentrations, highly smoothed closed values with high resolution and discrimination were obtained at these concentrations values. This verifies the high performance for this device at normal environmental conditions, giving it advantage to be used in such cases. However at very high sample concentration it goes out of the device range after 80 hours.

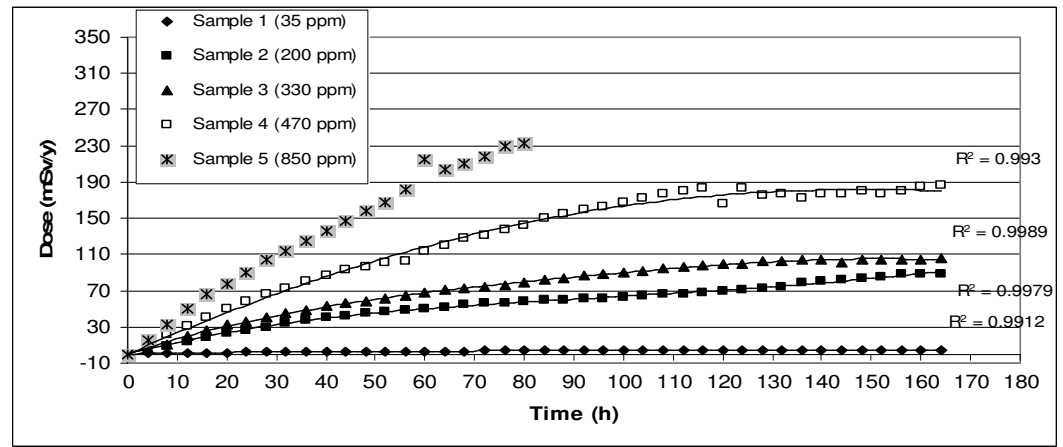

Fig. 9: Calculated annual dose (mSv/y) using the measurements of CRM device for all samples at low relative humidity and temperature versus time (h)

\section{CONCLUSIONS}

The comparison between the tested devices showed that a higher time $(\mathrm{t}=13 \mathrm{~min}$. $)$ is required to complete the surveillance process (from the beginning till the end of measurements) for both Tri-Met and RDA 200 devices while it needs from 1 to $3 \mathrm{~min}$. for RGM device. The CRM-1027 device takes about 1 to $2 \mathrm{sec}$. for the measurement but it needs to run at least $1 \mathrm{~h}$ before each measurement. These are based on the principals of the measuring devices and the theory of operation of the used instruments.

More stability for the RDA - 200 and Tri - Met 372 devices are detected at high temperature and high humidity due to the limited effect of high temperature and humidity on the sampling and counting instruments. From the other hand, a more stability for both RGM and CRM-1027 devices are clearly appeared at low temperature and low humidity conditions. This may be attributed to that they de- pend mainly on the electronic circuits which have a higher performance at these environmental conditions.

No human mistakes are found when using CRM device but small ones can be found when using RGM 1/1 device in the misreading of its analogue scale, while there are some expected human mistakes when using RDA-200 and Tri-Met-72 devices due to the use of stop watch for sampling time, the handling of the filter paper when removing from the sampling pump and applying to the RDA - 200 or Tri - Met 372 devices.

Small maintenance operations can be done easily and in short time for both RDA -200 and Tri-Met devices; while it is difficult to do maintenance for both RGM $1 / 1$ and CRM-1027devices which require a specialist to do that.

Large numbers of steps are needed for the use of RDA-200 and Tri-Met 372 devices (7 
steps). While RGM 1/1 device needs 3 steps and CRM device requires only 1 step to complete the whole process from the beginning till the end of measurements.

RGM device has the highest weight (14.5 $\mathrm{Kg}$ ) followed by RDA 200 device $(3 \mathrm{Kg})$. The weight of Tri-Met device and its accessories is $(2.5 \mathrm{Kg})$, while the weight of CRM device $(1 \mathrm{Kg})$.

The following Table shows the comparison between different used devices according to their comparison matrix time, cost, efficiency and ease of use.

Table 1: The inter-comparison between the used instruments

\begin{tabular}{|c|c|c|c|c|c|}
\hline & \multicolumn{2}{|c|}{ Grab Sampling Technique } & \multicolumn{2}{|c|}{ Continuous monitoring } \\
\hline & & Tri-met & RDA 200 & RGM & CRM \\
\hline \multicolumn{2}{|l|}{ Time } & $13 \mathrm{~min}$. & $13 \mathrm{~min}$. & $1.3 \mathrm{~min}$. & $60 \mathrm{~min}$. \\
\hline \multicolumn{2}{|l|}{ Cost } & $4 \mathrm{LE}$ & $4.75 \mathrm{LE}$ & 1L.E & $<1 \mathrm{LE}$ \\
\hline \multicolumn{2}{|c|}{ Efficiency } & $\begin{array}{r}\text { Good at high } \\
(\mathrm{T} \& \mathrm{H})\end{array}$ & $\begin{array}{l}\text { Good at high } \\
\text { (T \& H) }\end{array}$ & $\begin{array}{r}\text { Good at low } \\
\text { (T \& H) }\end{array}$ & $\begin{array}{r}\text { Good at low } \\
\text { (T \& H) }\end{array}$ \\
\hline \multirow{3}{*}{$\begin{array}{l}\text { Ease } \\
\text { of use }\end{array}$} & $\begin{array}{l}\text { No. of } \\
\text { steps }\end{array}$ & 7 steps & 7 steps & 3 steps & 1 step \\
\hline & Weight & $2.5 \mathrm{Kg}$ & $3 \mathrm{Kg}$ & $14.5 \mathrm{Kg}$ & $1 \mathrm{Kg}$ \\
\hline & $\begin{array}{l}\text { Training } \\
\text { ease }\end{array}$ & High & High & Moderate & Low \\
\hline
\end{tabular}

This study recommends applying RDA 200 and Tri- Met 372 devices at mines and mills according to their high performance and limited requirements to work at these places.

The application of CRM-1207 and RGM $1 / 1$ devices are suitable at laboratories is recommended according to their high performance and limited requirements.

It is very important to construct a complete comparison when choosing the set of devices and techniques for the optimum application and performance of surveillance process.

Good preparation for surveillance and monitoring radiation programs must include the best use of techniques and devices to achieve the goal of radiation protection which will help in decreasing the life-shortening percentage from ( $10 \%$ to $15 \%)$.

\section{REFERENCES}

Beckman, R. T., 1975. calibration Procedures for Radon and Radon Daughter Measurement Equipment. Mining Enforcement Safety Administration Report, MESA-IR-1005

Dalu, G.A., and Dalu, G., 1971. Automatic counter for direct measurement of Radon concentration. J. Aerosol Sci., 2, 247p .

Evans, R.D., 1969. Engineer's Guide to the Elementary Behaviour of Radon Daughters. Health Phys., 17, 229-252 .

Falk, J., 1982. Kalibrering av radon dotter mature. National Institute of Radiation Protection Rep., No. A, $82-19$.

Fontan, J.; Blanc, D., and Bouville, A., 1962. Emploi d'un System de Coincidences dans le Dosage Selectif du Radon et du Thoron Atmosphériques. Le Journ. de Phys., et le Radium Iome. 23, 333.

Grossi, C., 2001.Inter-comparison of different direct and indirect methods to determine radon flux from soil. Radiation Measurements. 46, 112-118.

Hill, A., 1975. Rapid Measurement of Radon Decay Products, Unattached Fractions and Working Level Values of Mine Atmospheres. Health Phys., 28, $472-474$.

ICRP Publication 31, 1980. Report of the ICRP Task Group on Biological Effects of inhaled Radionuclides. Annals of the ICPR, 4(1/2), Pergamon Press. Oxford.

Jacobi, W., 1964. A Double-filter Device to Measure Radon and Thoron in the Breath. Assessm. of Radioact. in Man. I, IAEA, Vienna, Austria.

Jonassen, N., and Clements, W. E., 1974. Determination of ${ }^{222} \mathrm{Rn}$ Concentrations by Integrated Count Method. Health Phys., 27, 347.

Kusnetz, H.L.,1956. Radon daughters in mine atmospheres-A filed method for determining concentrations, Am. Ind. Hyg. Assoc. J., 1785 .

Lawrence Berkeley Laboratory, 1981.Proceedings 
of The Meeting of An AD Hoc Committee on Interlaboratory Calibration of Radon and Radon Daughters Instrumentation". Lawrence Berkeley Laboratory, Report, Berkeley, Calif., USA.

Lucas, H.F.,1957. Improved Low-level Alphascintillation Counter for Radon. Rev. Sci. Inst., $28,680-683$.

Martz, D.E.; Holleman, D.F.; Mc Curdy, D.E., and Schiager, K. J., 1969. Analysis of Atmospheric Concentrations of $\mathrm{RaA}, \mathrm{RaB}$ and $\mathrm{RaC}$ by Alpha Spectroscopy. Health Phys., 17, 131 -138 .

Rolle, R., 1968. Improved radon daughter monitoring procedure. Am. Ind. Hyg. Assoc. J., 30 2153.

Rolle, R.,1972. Rapid Working Level Monitoring. Health Phys., 22, 233-238.

IAEA Safety Series No. 43,1979. The International Atomic Energy Agency and The International Labour Organization. "Manual on Radiological Safety in Uranium and Thorium Mines and Mills". Vienna.

Salem, M.M.A., 2008. Radio Element Distribution in Some Underground Mining Works in Gabal Gattar Area and their Impact on Environmental Conditions, Eastern Desert, Egypt. PhD Thesis, Fac. Sci., Banha Univ., Egypt.

Tawfik, M.N, 2011. Radon Evaluation Studies Using Various Monitoring Devices ,Pilot Plant Case Study. M.Sc. Thesis ,Fac. Sci. , Ain Shams Univ. ,Egypt.

Thomas, J. W., and Le Clare, P. C., 1970. A study of the 2-Filter Method for ${ }^{222} \mathrm{Rn}$ ". Health Phys., $18,113$.

Thomas, J.W., 1972. Measurement of radon daughters in air, Health Phys. 23783.

Thomas, J. W., 1977.An Environmental Radon and Thoron Monitor. HASL - 325 (NTIS) .

Tsivoglou, E.C.; Ayer, H.E., and Holady, D.A., 1953. Occurrence of Non-equilibrium Atmospheric Mixtures of Radon and Its Daughters. Nucleonics., 11, $40-46$.

Wrenn, M.W.; Spitz, H., and Cohen, N., 1975. Design of A Continuous Digital-output Environmental Radon Monitor. IEEE Trans. Nucl. Sci., NS - 22, 645 .

$$
\text { مراقبة التقتيات الفعالة و المستمرة لقياس الر ادون في ظروف بيئية محكمة }
$$

الرصد المستمر لتركيز ات غاز الر ادون هي طريقة هامة لدر اسة اثار التهوية علي مستويات تركيز

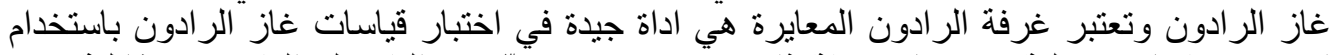

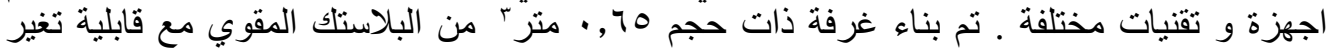

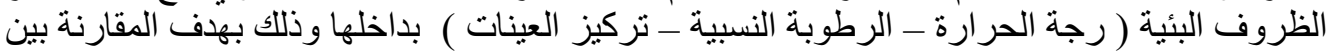

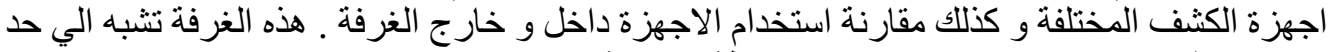

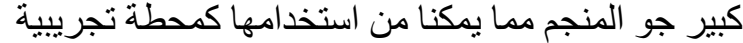
لهذا الغرض تم استخدام اربعة اجهزة مختلفة لقياس تركيز غاز الر ادون , اثنين للقياسات الفعالة RMG 1/1 and) و الاخران لتقنية القياس المستمر و همان (RDA-200 and TRI-MET -372)

(CRM-1027

تم اجر اء التجارب في في ظروف بيئية مختلفة , الاولي باستخدام درجة حرارة عالية ( • ع درجة

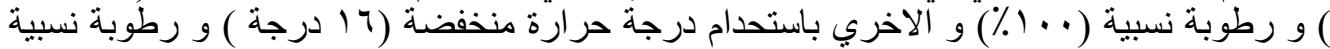

اظهرت النتائج تدني مستوي الاستقرار في القياسات مع التغيير في الظروف البيئية , و قد 
لوحظ المزيد من الاستقرار لأجهزة (RDA-200 and TRI-MET -372) في درجة الحرارة العالية و الرطوبة العالية , من ناحية اخري لوحظ ظهور المزيد من الاستقرار لكلا من (RMG 1/1 and

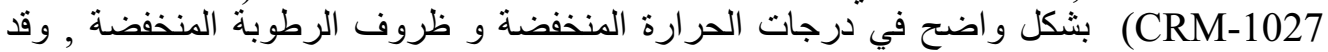

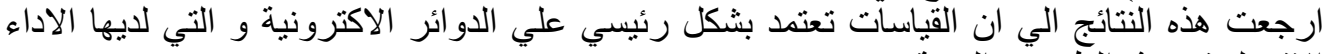

